\title{
Pengaruh Variasi Suhu Pengeringan Terhadap Pembuatan Simplisia Daun Mimba (Azadirachta Indica)
}

\author{
The Effect Of Drying Temperature Variation On The Simplicia Of \\ Mimba Leaf (Azadirachta Indica) \\ Diana Lady Yunita Handoyo, M. Eko Pranoto \\ Program Studi Farmasi, Fakultas Ilmu Kesehatan, Universitas Ibrahimy \\ Email: diana@ibrahimy.ac.id
}

\begin{abstract}
ABSTRAK
Salah satu tanaman yang telah lama digunakan sebagai obat tradisional adalah mimba (Azadirachta indica). Tanaman obat yang digunakan biasanya dalam bentuk simplisia (bahan tumbuhan yang belum mengalami pengolahan apapun dan umumnya berupa bahan yang dikeringkan). Tujuan dari penelitian ini yaitu untuk mengetahui pengaruh variasi suhu pengeringan terhadap pembuatan simplisia daun mimba (Azadirachta indica). Penelitian ini merupakan Jenis penelitian ini adalah penelitian eksperimental laboratorium dengan sampel daun mimba berasal dari daerah Desa Sumberejo Kecamatan Banyuputih Kabupaten Situbondo. Pengeringan menggunakan metode pengeringan matahari langsung, metode pengeringan dengan sinar matahari langsung ditutup menggunakan kain hitam dan pengeringan menggunakan metode oven dengan variasi suhu $45^{\circ} \mathrm{C}, 50^{\circ} \mathrm{C}, 60^{\circ} \mathrm{C}$. Hasil penelitian menunjukkan bahwa metode pengeringan berpengaruh terhadap mutu simplisia daun mimba. Pengeringan menggunakan oven dengan variasi suhu $45^{\circ} \mathrm{C}$ dan $50^{\circ} \mathrm{C}$ merupakan pengeringan yang baik karena didapat hasil warna daun hijau cerah, tidak berasa, bau khas daun mimba, daun berbentuk memanjang lanset bengkok, tepi daun bergerigi, rapuh saat digenggam, terdapat bau khas.
\end{abstract}

Kata Kunci: Daun Mimba, Suhu, Simplisia

\begin{abstract}
One of the plants that has long been used as a traditional medicine is neem (Azadirachta indica). The medicinal plants used are usually in the form of simplicia (plant material that has not undergone any processing and is generally in the form of dried material). The purpose of this study was to determine the effect of drying temperature variations on the manufacture of neem (Azadirachta indica) leaf simplicia. This research is a type of research that is a laboratory experimental study with samples of neem leaves from the village of Sumberejo, Banyuputih District, Situbondo Regency. Drying uses the direct sun drying method, the drying method with direct sunlight is covered using a black cloth and drying using the oven method with temperature variations of $45^{\circ} \mathrm{C}, 50^{\circ} \mathrm{C}, 60^{\circ} \mathrm{C}$. The results showed that the drying method affected the quality of neem leaf simplicia. Drying using an oven with a temperature variation of $45{ }^{\circ} \mathrm{C}$ and $50{ }^{\circ} \mathrm{C}$ is good drying because the results are bright green leaf color, tasteless, a distinctive smell of neem leaves, curved lancet-shaped leaves, jagged leaf edges, brittle when held, there is a distinctive smell.
\end{abstract}

Keywords: Neem Leaves, Temperature, Simplicia

\section{PENDAHULUAN}

Meningkatnya pemakaian tanaman obat dalam satu decade terakhir ini berbanding lurus dengan berkembangnya industri jamu atau obat tradisional, farmasi, kosmeti, minuman 
dan makanan. Pemanfaatan tanaman yang biasanya digunakan berupa simplisia yaitu bahan tanaman yang masih belum mengalami perubahan bentuk dan hanya dikeringkan saja. Selama ini banyak Masyarakat yang telah menggunakan simplisia baik berupa akar, herba, biji, daun dan batang, untuk memenuhi kebutuhan kesehatan yaitu sebagai obat untuk mengobati berbagai macam penyakit (Atjung, 1982).

Tanaman obat tradisional telah banyak dimanfaatkan oleh Masyarakat dalam menanggulangi berbagai macam penyakit. Selain itu, banyak penelitian tentang obat tradisional sebagai hasil dari kajian ilmiah tentang khasiat atau manfaat dari suatu tanaman yang berpotensi sebagai obat. Selain itu berbagai penelitian juga mengembangkan senyawa penuntun sintesis dalam pembuatan senyawa obat baru. Tanaman yang umum digunakan oleh Masyarakat sebagai obat tradisional adalah tanaman mimba (Azadirachta indica). Pemanfaatan tanaman mimba di Indonesia sebagai obat tradisional selama ini belum diimbangi oleh standarisai kandungan dan kegunaanya dan penelitian mengenai hal tersebut masih sangat sedikit. Tanaman mimba selama ini banyak tumbuh secara diliar diberbagai daerah di Indonesia dan kurang pemanfaatannya, saat ini beberapa peneliti sudah mulai mengenal dan meneliti potensi tanaman bimba yang berpotensi sebagai obat tradisional(Atjung, 1982).

Bagian tanaman mimba yang biasanya dimanfaatkan sebagai simplisia adalah bagian daunnya. Kandungan yang ada dalam daun mimba misalnya golongan limonoid, limonoid merupakan metabolit sekunder yang sudah teridentifikasi dalam daun mimba antara lain azadirachtin, salanin, meliantriol dan nimbin. Metabolit sekunder merupakan salah satu indicator dalam menentukan manfaat sebagai tanaman obat dan dipengaruhi oleh tempat tanaman tersebut tumbuh, perlakuan sebelum dan sesudah panen. Perlakuan setelah panen merupakan tahap awal pengolahan dari bahan obat yang meliputi sortasi, pembersihan bahan, perajangan, pengeringan dan penyimpanan. Tahap pengeringan merupakan tahap yang paling penting dalam menentukan kandungan yang ada dalam bahan, selain itu setiap tahapan harus dilakukan secara tepat dan sesuai standar mutu sehingga tidak merusak 
kandungan senyawa yang ada di dalamnya (Syukur dan Hernani, 2001).

Bahan alamiah yang belum mengalami pengolahan apapun atau hanya dikeringkan saja dan digunakan sebagai obat dinamakan simplisia (Depkes, 1985). Pengeringan merupakan proses pengurangan kadar air atau pemisahan air dalam jumlah yang relatif sedikit dari bahan dengan bantuan energi panas. Tujuan dari proses pengeringan yaitu mengurangi kandungan air di dalam bahan dan bahan tidak mudah rusak, sehingga dapat disimpan dalam jangka waktu yang lama. Pengurangan kadar air dapat menghentikan proses enzimatik sehingga dapat mencegah penurunan mutu atau kerusakan simplisia. Keberadaan air dalam sampeldapat memicu pertumbuhan kapang dan mikroba lainnya. Selama bahan masih memiliki kandungan air yang tinggi beberapa enzim tertentu dalam sel akan menguraikan senyawa aktif,meskipun setelah selnya dalam keadaan mati. Oleh karena itu, suhu dalam proses pengeringan sangat mempengaruhi kualitas dan mutu dari simplisia (Rachmawan, 2001).

Tujuan dari penelitian ini yaitu untuk mengetahui pengaruh variasi suhu pengeringan terhadap pembuatan simplisia daun mimba (Azadirachta indica).

\section{METODE PENELITIAN}

Jenis penelitian ini merupakan penelitian eksperimental laboratorium dengan sampel daun mimba berasal dari daerah Desa Sumberejo Kecamatan Banyuputih Kabupaten Situbondo. Pengeringan menggunakan metode pengeringan matahari langsung, metode pengeringan dengan sinar matahari langsung ditutup menggunakan kain hitam dan pengeringan menggunakan metode oven dengan variasi suhu $45^{\circ} \mathrm{C}$, $50^{\circ} \mathrm{C}, 60^{\circ} \mathrm{C}$.

Penelitian ini dilakukan di Laboratorium Farmakognosi Program Studi Farmasi Fakultas Ilmu Kesehatan, Universitas Ibrahimy. Penelitian ini dilakukan pada bulan Maret-Agustus 2019.

Alat yang digunakan untuk penelitian ini adalah neraca analitik, timbangan, beaker glass, pengaduk, nampan plastik, kain hitam, kasa, sertas saring, ayakan, oven, wadah plastik, pisau, blender atau alat penghalus.

Bahan yang digunakan antara lain daun mimba, air atau akuades. 


\section{Penyiapan Bahan Penelitian}

Pengambilan sampel dilakukan dengan cara dipilih daun yang terletak di bagian cabang batang yang menerima sinar matahari langsung. Sampel diambil menggunakan tangan atau menggunakan alat yang tidak mengandung logam, dikarenakan berpotensi merusak kandungan metabolit sekunder oleh reaksi dengan logam tersebut. Bahan sampel yang telah dikumpulkan kemudian disimpan di dalam wadah yang bukan terbuat dari logam. Pilih daun yang mulus dan tidak terdapat cacat sedikitpun. Daun yang baik tidak terdapat cacat, kotoran, debu, ulat, rusak atau benda asing lain. Pencucian dilakukan untuk menghilangkan bahan pengotor lainnya yang melekat pada simplisia. Pencucian dilakukan dengan menggunakan air bersih yang mengalir sampai daun benar-benar terbebas dari kotoran maupun benda asing.

Perajangan dilakukan menggunakan pisau dan diberi alas sebelum dilakukan pemotongan, pemotongan bahan simplisia harus sama ukurannya. Bahan simplisia yang telah dirajang dengan ukuran yang sama dimaksudkan untuk membantu mempercepat proses pengeringan.

\section{Metode Pengeringan}

Pengeringan dengan sinar matahari langsung dan pengeringan dengan ditutupi kain hitam dilakukan selama 48 jam, tergantung dari keadaan cuaca. Pengeringan menggunakan oven dilakukan selama 6 sampai 8 jam.

a. Pengeringan dengan sinar matahari langsung

Bahan yang telah dilakukan proses perajangan atau dalam bentuk yang lebih kecil kemudian ditimbang sebanyak 300gram, wadah yang digunakan untuk pengeringan tersebut mempunyai dasar yang berlubang-lubang seperti anyaman bambu dimaksudkan agar aliran udara dari atas ke bawah atau sebaliknya berjalan lancar.

b. Pengeringan dengan ditutupi kain hitam menggunakan bantuan sinar matahari langsung

Bahan simplisia yang telah dirajang kemudian ditimbang sebanyak $300 \mathrm{~g}$, wadah yang digunakan untuk pengeringan tersebut mempunyai dasar yang berlubang-lubang seperti anyaman bambu dimaksudkan agar aliran udara dari atas ke bawah atau sebaliknya berjalan lancar. Setelah itu ditutup 
bagian atasnya menggunakan kain hitam kemudian langsung dijemur.

c. Pengeringan menggunakan oven Bahan yang telah dirajang kemudian ditimbang sebanyak $300 \mathrm{~g}$ untuk masing-masing variasi suhu, bahan simplisia kemudian dimasukan kedalam oven, atur suhu sesuai dengan metode uji yaitu pada suhu $45^{\circ} \mathrm{C}$, suhu $50^{\circ} \mathrm{C}$, dan suhu $60^{\circ} \mathrm{C}$.

\section{Pemeriksaan Mutu Simplisia Daun} Mimba

Pengujian mutu yang dilakukan pada simplisia daun Mimba (A. indica) adalah sebagai berikut :

a. Organoleptik

Pengujian organoleptik yaitu menggunakan panca indra untuk melakukan analisa yaitu warna, bentuk, rasa dan bau. b. Makroskopik

Penggunaan panca indera dengan bantuan alat kaca pembesar untuk mengamati ciri-ciri luar simplisia meliputi bentuk morfologi dan tekstur.

Data hasil disajikan dalam tabel dan penjelasan deskriptif meliputi hasil pengujian mutu simplisia yang telah dilakukan perlakuan variasi suhu. Data hasil penelitian meliputi data organoleptik dan makroskopik simplisia daun mimba pada setiap perlakuan variasi suhu.

\section{HASIL DAN PEMBAHASAN}

Berdasarkan hasil uji organolepik simplisia daun mimba diperoleh data pada tabel 1 dan hasil uji makroskopis dapat dilihat pada tabel 2 .

Tabel 4.1 Hasil Uji Organoleptik simplisia Daun Mimba

\begin{tabular}{|c|c|c|c|c|c|c|}
\hline \multirow[b]{2}{*}{$\begin{array}{c}\text { Organol } \\
\text { eptik }\end{array}$} & \multicolumn{2}{|c|}{ Sinar Matahari } & \multicolumn{3}{|c|}{ Oven } & \multirow{2}{*}{$\begin{array}{c}\text { Kontrol } \\
\text { Diangin- } \\
\text { angin }\end{array}$} \\
\hline & Langsung & $\begin{array}{c}\text { Ditutup Kain } \\
\text { Hitam }\end{array}$ & Suhu $45^{\circ} \mathrm{C}$ & Suhu $50^{\circ} \mathrm{C}$ & Suhu $60^{\circ} \mathrm{C}$ & \\
\hline Warna & $\begin{array}{l}\text { Hiaju } \\
\text { kehitaman }\end{array}$ & $\begin{array}{l}\text { Hiaju- } \\
\text { kecoklatan }\end{array}$ & Hijau cerah & Hijau cerah & $\begin{array}{l}\text { Hijau- } \\
\text { kecoklatan }\end{array}$ & $\begin{array}{l}\text { Hijau- } \\
\text { kecoklatan }\end{array}$ \\
\hline Rasa & $\begin{array}{l}\text { Tidak } \\
\text { Berasa }\end{array}$ & Tidak berasa & Tidak berasa & Tidak berasa & $\begin{array}{l}\text { Tidak } \\
\text { berasa }\end{array}$ & Tidak berasa \\
\hline Bau & Bau Khas & Bau khas & Bau khas & Bau khas & Bau khas & Bau khas \\
\hline
\end{tabular}


Tabel 4.2 Tabel Uji Makroskopik

\begin{tabular}{|c|c|c|c|c|c|c|}
\hline \multirow[b]{2}{*}{ Makroskopik } & \multicolumn{2}{|c|}{ Sinar Matahari } & \multicolumn{3}{|c|}{ Oven } & \multirow{2}{*}{$\begin{array}{c}\text { Kontrol } \\
\text { Diangin- } \\
\text { angin }\end{array}$} \\
\hline & Langsung & $\begin{array}{c}\text { Ditutup Kain } \\
\text { Hitam }\end{array}$ & Suhu $45^{\circ} \mathrm{C}$ & Suhu $50^{\circ} \mathrm{C}$ & Suhu $60^{\circ} \mathrm{C}$ & \\
\hline $\begin{array}{l}\text { Bentuk } \\
\text { Morfologi }\end{array}$ & $\begin{array}{l}\text { Tepi daun } \\
\text { bergerigi } \\
\text { dan licin } \\
\text { dibagian } \\
\text { daun }\end{array}$ & $\begin{array}{l}\text { Tepi daun } \\
\text { bergerigi dan } \\
\text { licin dibagian } \\
\text { daun }\end{array}$ & $\begin{array}{l}\text { Tepi daun } \\
\text { bergerigi } \\
\text { dan licin } \\
\text { dibagian } \\
\text { daun }\end{array}$ & $\begin{array}{l}\text { Tepi daun } \\
\text { bergerigi } \\
\text { dan licin } \\
\text { dibagian } \\
\text { daun }\end{array}$ & $\begin{array}{l}\text { Tepi daun } \\
\text { bergerigi } \\
\text { dan licin } \\
\text { dibagian } \\
\text { daun }\end{array}$ & $\begin{array}{l}\text { Tepi daun } \\
\text { bergerigi dan } \\
\text { licin dibagian } \\
\text { daun }\end{array}$ \\
\hline Tekstur & $\begin{array}{l}\text { Rapuh saat } \\
\text { digenggam }\end{array}$ & $\begin{array}{l}\text { Sedikit basah } \\
\text { saat } \\
\text { digenggam }\end{array}$ & $\begin{array}{l}\text { Rapuh saat } \\
\text { digenggam }\end{array}$ & $\begin{array}{l}\text { Rapuh saat } \\
\text { digenggam }\end{array}$ & $\begin{array}{l}\text { Rapuh saat } \\
\text { digenggam }\end{array}$ & $\begin{array}{l}\text { Sedikit basah } \\
\text { saat } \\
\text { digenggam }\end{array}$ \\
\hline
\end{tabular}

\section{Hasil Uji Organoleptik}

Daun mimba segar memiliki warna hijau cerah dan setelah mengalami proses pengeringan warna daun berubah menjadi lebih gelap, sehingga terdapat perbedaan warna yang signifikan. Perbedaan terlihat pada pengeringan menggunakan sinar matahari langsung, pengeringan sinar matahari yang ditutup ditutup kain hitam, pengeringan dengan oven suhu $60^{\circ} \mathrm{C}$ dan diangin-angin, warna daun menjadi hijau kehitam-hitaman dan kecoklatan. Sedangkan pengeringan menggunakan metode oven dengan variasi suhu $45^{\circ} \mathrm{C}$ dan $50^{\circ} \mathrm{C}$ mempunyai warna hijau cerah.

Perubahan warna daun bisa disebabkan oleh terjadinya proses degradasi klorofil dari warna hijau menjadi hijau kecoklatan sampai kehitaman selama proses pengeringan. Pada klorofil sifat yang paling penting yaitu kelabilan yang sensitive terhadap suhu, oksigen dan cahaya. Selain itu, kandungan air yang tersisa di daun pada kadar tertentu bisa menjadi media pertumbuhan kapang dan terdapat enzim tertentu dalam sel bisa aktif kembali untuk menguraikan senyawa aktif. Pada tumbuhan hidup proses enzimatik dan adanya kadar air yang tinggi tidak terjadi hal tersebut karena adanya keseimbangan proses metabolisme seperti fotosintesis, transformasi dan penggunaan organel sel.

Tanaman mimba memiliki habitus pohon dengan tinggi 8-15 meter, percabangan simpodial, kulit batangnya mengandung gum dan rasanya pahit. Daunnya majemuk menyirip gasal dan berpasangan, anak daun memiliki bentuk helaian memanjang lanset bengkok, panjang 3$10 \mathrm{~cm}$ dan lebar $0.5-3.5 \mathrm{~cm}$, pangkal 
daun runcing tidak simetri, ujung rucing sampai meruncing, tepi daun bergerigi kasar, remasan daun berasa pahit, warna hijau muda hingga hijau tua. Bunga banci, susunan bunga malai, terletak di ketiak daun paling ujung, panjang susunan 5-30 cm, pangkal berambut halus dengan panjang 1-2 mm.

Setiap organ tanaman mimba memiliki kandungan senyawa yang berbeda dan telah banyak penelitian tentang kandungan bioaktif dan aktivitas biologinya. Pada penelitian biji mimba atau minyak biji mimba diketahui kandungannya memiliki aktivitas sebagai antibakteri dan antifungi. Pada kulit batangnya memiliki aktivitas antitumor, antibakteri, antiimunodulator dan antiinflamasi. Daun mimba memiliki kandungan yang berfungsi sebagai antifungi dan anti serangga karena mengandung senyawa azadirachtin yang paling dominan. Selain itu ekstrak daun mimba juga berfungsi sebagai fungisida alami dalam pengendalian penyakit antraknosa pada apel setelah panen dan sebagai insektisida terhadap larva Aedes aegypti (Sulaiman 1997).

\section{Hasil Uji Makroskopik}

Pada uji makroskopik dilakukan pengamatan dan terdapat perbedaan dari segi tekstur dari simplisia daun mimba. Pengeringan dengan metode kain hitam dan diangin-angin tekstur daun sedikit basah apabila digenggam. Hal ini disebabkan oleh metode pengeringan diangin anginkan dan menggunakan kain hitam tidak terlau terpapar panas, sehingga membutuhkan waktu yang relative lama dibandingkan metode yang lain. Pada proses pengeringan dipengaruhi oleh suhu dan aliran, semakin tinggi suhu dan aliran udara maka proses pengeringan akan berlangsung relatif cepat. Hal ini disebabkan karena semakin tinggi suhu udara maka energi panas yang dibawa juga besar dan jumlah masa cairan yang diuapkan dari permukaan bahan juga semakin banyak (Gunawan dan Mulyani 2004).

Pembuatan simplisia terdapat beberapa macam cara antara lain proses pengeringan fermentasi, proses khusus dan menggunakan air. Pada penelitian ini proses pengeringannya menggunakan variasi suhu yang dilakukan setelah proses pemanenan bahan baku secara langsung. Secara umum fungsi dari proses pengeringan adalah mengurangi kadar air yang dapat menghambat pertumbuhan bakteri serta kapang, bahan lebih awet saat disimpan, 
memudahkan penyimpanan dan perlakuan selanjutnya lebih mudah (Gunawan dan Mulyani 2004).

Pengeringan sebaiknya menggunalan suhu yang tidak terlalu tinggi baik secara alami menggunakan sinar matahari maupun suhu buatan seperti oven. Suhu yang tinggi memang mempercepat proses pengeringan namun seringkali tidak merata terutama bagian dalam bahan baku masih ada yang belum kering sempurna. Sebaliknya, jika suhu pengeringan terlalu rendah prosesnya akan berjalan lambat dan berpotensi adanya jamur dan mikroba yang berkembang. Jadi secara umum biasanya suhu yang efektif untuk pengeringan berkisar kurang dari 60$70^{\circ} \mathrm{C}$ (Gunawan dan Mulyani 2004).

Tahapan proses pembuatan simplisia meliputi pengumpulan bahan baku, sortasi basah, pencucian, pengeringan, pengayakan atau penghalusan dan penyimpanan. Proses pengumpulan bahan baku dilakukan dengan cara memanen atau mengumpulkan bahan segar langsung dari tanamannya. Hal yang perlu diperhatikan dalam proses pengumpulan antara lain umur, waktu pemanenan dan habitat. Waktu pemanenan erat kaitannya dengan pembentukan

kandungan senyawa aktif di dalam tanaman tersebut, waktu pemanenan yang tepat secara umum pada saat senyawa yang terbentuk dalam jumlah besar dengan rentang umur tertentu. Misalnya pemanenan umbi lapis bawang dilakukan pada saat akhir pertumbuhan (Gunawan dan Mulyani 2004).

Proses selanjutnya yaitu sortasi, proses ini dilakukan pemilahan hasil panen ketika tanaman masih segar dengan cara memisahkan tanah, kerikil, rumput liar dan bahan tanaman lainnya yang tidak diinginkan, selain itu juga bisa memisahkan bagian tanaman yang cacat atau rusak dimakan ulat (Gunawan dan Mulyani 2004). Pada tahap pencucian bertujuan untuk memisahkan kotoran atau bahan asing lainnya yang menempel pada bahan. Proses pencucian biasanya menggunakan air bersih dan beberapa bahan yang mengandung senyawa atau zat mudah larut dalam air agar dilakukan dengan waktu secepat mungkin (Prastowo 2013). Beberapa bahan membutuhkan perajangan supaya memperluas permukaan dan proses pengeringannya berlangsung relative cepat (Gunawan dan Mulyani 2004). 
Tahap yang utama yaitu proses pengeringan, pada proses ini terjadi pengeluaran air dari sampel secara termal sehingga menghasilkan produk kering. Faktor eksternal yang mempengaruhi proses pengeringan adalah suhu, kelembaban, tekanan udara dan kecepatan, sedangkan faktor internal yang berpengaruh antara lain kadar air, bentuk, luas permukaan dan kondisi fisik sampel. (Gunawan dan Mulyani 2004). Pengeringan dapat dilakukan secara tradisional dengan hanya dijemur dibawah sinar matahari denga kisaran waktu 2-3 hari, sedangkan penegeringan yang modern sudah menggunakan bantuan alatseperti oven, rak pengering atau fresh dryer dengan kisaran waktu sekitar 6-8 jam saja dan suhu dapat di atur sesuai kebutuhan (Gunawan dan Mulyani 2004). Penurunan kualitas mutu simplisia yang disebabkan oleh kadar air sampel dapat dicegah dengan proses pengeringan, sehingga reaksi enzimatik tidak akan berlangsung. Kadar air yan ada dalam sampel supaya tidak terjadi proses reaksi enzimatik harus kurang dari 10\% (Prastowo 2013).

Tahapan selanjutnya setelah dihaluskan dengan mengsin penggiling supaya memudahkan dalam proses selanjutnya yaitu proses pengayakan. Proses pengayakan bertujuan bahan supaya mendapatkan sebuk dengan luas permukaan bahan dengan pelarutnya lebih cepat larut dan senyawa yang harapkan dapat terserap dengan baik. Tahapan terakhir yaitu penyimpanan simplisia, hal ini dilakuakan untuk mempertahankan mutu simplisia dalam kurun waktu tertentu sebelum akhirnya dilakukan untuk proses selanjutnya. Hal-hal yang harus diperhatikan dalam proses penyimpanan antara lain oksidasi, cahaya, kelembaban,reaksi internal bahan, dehidrasi, kontaminasi, kapang dan serangga (Prastowo 2013).

\section{SIMPULAN DAN SARAN}

Berdasarkan hasil penelitian maka dapat disimpulkan bahwa metode pengeringan berpengaruh terhadap mutu simplisia daun mimba. Pengeringan menggunakan oven dengan variasi suhu $45^{\circ} \mathrm{C}$ dan $50^{\circ} \mathrm{C}$ merupakan pengeringan yang baik karena didapat hasil warna daun hijau cerah, tidak berasa, bau khas daun mimba, daun berbentuk memanjang lanset bengkok, tepi daun bergerigi, rapuh saat digenggam, terdapat bau khas.

Saran penelitian selanjutnya perlu adanya penelitian lebih lanjut 
mengenai metode lain dan dapat dilakukan pengujian kandungan senyawa pada masing-masing simplisia dengan pengeringan berbeda tersebut.

\section{DAFTAR PUSTAKA}

Dixa S, Singh V.S. Isolation and Characterization of Flavonoids in Urena lobata L. Eurpean Journal of Medicinal Plants, Vol. 1. 2016. hal 1- 6.

Fagbohun E.D, Asare R.R, Egbebi A.O. Chemical Composition and Antimicrobial Activities of Urena lobata L. Journal of Medicinal Plants Reserch Vol. 6. 2012

Prasetyo, Inoriyah E. Pengelolaan Budidaya Tanaman Obatobatan (Bahan Simplisia). Bengkulu: Badan Penerbitan Fakultas Pertanian UNIB; 2013.

Depkes RI. Cara Pembuatan Simplisia. Departemen Kesehatan Republik Indonesia. Jakarta: DEPKES; 1985.

Muller J, Heindl. Drying Of Medical Plants In R.J. Bogers,
L.E.Cracer, and Lange D, (eds). Medical and Aromatic Plant. The Netherland: Springer. 2006. p.237-252.

Rohyami Y, Identifikasi Flavonoid dari Ekstrak Metanol Daging Buah Mahkota Dewa (Phaleria macrocarpa Boerl) Menggunakan Spektrofotometer $U V$-Vis dan FT-IR, Laporan Penelitian PDM DIKTI. 2008.

Rachmawan O. Pengeringan, Pendinginan dan Pengemasan Komoditas Pertanian. Buletin Departemen Pendidikan Nasional. Jakarta: 2001.

Nurhasanah T. Lukmayani Y. Kodir R.A. Karakterisasi Simplisia dan Ekstrak Serta Identifikkasi Histokimia Daun Pulutan (Urena lobata L.). Jurnal Farmasi Prodi Farmasi, Fakultas Matematika dan Ilmu Pengetahuan Alam. Universitas Islam Bandung, Vol. 5, No. 1. 2019.

Markham K.R. Cara Mengidentifikasi Flavonoid. Terjemahan Kosasih Padmawinata. Bandung: Badan Penerbit Institut Teknologi Bandung; 1988. 